KIRTHIGA, O.M., RAJENDRAN, L. and FERNANDEZ, C. 2018. Kinetic mechanism for modelling of electrochemical mediatedenzyme reactions and determination of enzyme kinetics parameters. Russian journal of electrochmistry [online], 54(11), pages 783-795. Available from: https://doi.org/10.1134/s1023193518110034

\title{
Kinetic mechanism for modelling of electrochemical mediated enzyme reactions and determination of enzyme kinetics parameters.
}

\author{
KIRTHIGA, O.M., RAJENDRAN, L, FERNANDEZ, C..
}

2018

This is a post-peer-review, pre-copyedit version of an article published in Russian Journal of Electrochemisty.

The final authenticated version is available online at: http://dx.doi.org/10.1134/s1023193518110034 
Kinetic mechanism for modelling of electrochemical mediated enzyme reactions and determination of enzyme kinetics parameters

O. M. Kirthiga ${ }^{1}$, L. Rajendran ${ }^{1, *}$, Carlos Fernandez ${ }^{2}$

${ }^{*}$ Corresponding author: Cell: 91- 9442228951

${ }^{1}$ Department of Mathematics, Sethu Institute of Technology, Kariapatti 626115.

${ }^{2}$ Department of AnalyticalChemistry, School of Pharmacy and Life Sciences, Robert Gordon University, Aberdeen (UK)

E-mail address: raj_sms@rediffmail.com (L. Rajendran)

kirthi024@gmail.com(O. M. Kirthiga)

c.fernandez@rgu.ac.uk (Carlos Fernandez) 


\begin{abstract}
The non-steady state current density for reversible electrochemical coupled with a homogeneous enzyme reaction and a constant potential is presented in this manuscript for the first time. The model is based on non-stationary diffusion equations with semi infinite boundary condition containing a nonlinear term related to the kinetics of an enzymatic reaction. The nonlinear differential equation for the mediator is solved for reversible homogeneous enzyme reaction. Approximate analytical expressions for the concentration of the mediator and corresponding current for non-steady state conditions are derived. Kinetic parameters are also determined such as Michaelis-Menten constants for substrate (KMS) and mediator (KMM) as well as catalytic

rate constant (kcat).. Upon comparison, we found that the analytical results of this work are in excellent agreement with the numerical (Matlab program) and existing limiting case results. The significance of the analytical results has been demonstrated by suggesting two new graphical procedures for estimating the Michaelis-Menten constants for substrate $\left(K_{M S}\right)$ and mediator $\left(K_{M M}\right)$ as well as catalytic rate constant $\left(k_{c a t}\right)$ from the current densities.
\end{abstract}


Keywords: Mathematical modelling, Non-linear reaction diffusion equations, Enzyme electrode, Mediated enzyme reactions.

\section{Introduction}

Cyclic voltammetry has been used for the measurement of electroanalytical properties of analytes by means of modified electrodes. During the past two decades, cyclic voltammetry has attracted a great interest in electrochemical reactions, in particular coupled with a mediated enzyme reaction. Since Nicholson and Shain [1] first reported their theoretical treatment of cyclic voltammetry, it has commonly been used as an analytical method to explore reaction kinetics.

Simulations of mediated enzyme electrochemistry have been extensively reported [2-5]. Bartlett and Pratt have reviewed and analyzed previous works on the simulation of enzyme electrodes [6]. Simulations are classified as either approximate analytical methods or numerical methods. To obtain an approximate analytical solution, approximation and classification of each different condition are needed. On the other hand, digital simulation to obtain a numerical solution can be applied to any case, and neither simplification nor classification is necessary [7]. Many digital simulations for steady-state and non steady-state responses of enzyme electrochemistry have been reported [8-12]. However, concentration polarization of the substrate in the vicinity of an electrode surface has never been considered for cyclic voltammetric simulation of a mediated enzyme reaction. A cyclic voltammetric simulation of the homogeneous case has been described in a preliminary way by Bartlett and Pratt [6] and compared to the simulated cyclic voltammetric system with the simple EC’ system. Unfortunately, no further studies have been reported.

Osman and coworkers [13] analyzed and discussed about the validation of model against the experimental polarization and power curves under different conditions. Do et al. [14] developed and investigated the influence of the electrode structure and the immobilization procedure, for two types of enzymatic electrodes. A computation model for microbial fuel cells (MFC) based on redox mediators was described by Picioreanu et al. [15]. Voltage and power current characteristics can also be calculated at different moments in time to evaluate the limiting regime in which the MFC operates. Ideally the most powerful approach is to combine the use of approximate analytical solutions that provide physical insights into the nature of the rate limiting processes and the physical behavior of the system with numerical approaches that can be used to fit the full range of experimental data and to extract the best estimates of the controlling kinetic parameters. Eswari et al. [16,17] derived analytical expressions of concentration and current for 
an EC and EC' reaction using Laplace transform method for cyclic voltammetry. The simulation of an idealized model for particular type of voltammetry and focusing on the effects of adsorption coverage and binding strength on the surface on the voltammetry response was stated [18]. Molina et al. [19] presented a series of simple analytical equations for multi electron transfer processes in cyclic voltmmetry and staircase cyclic voltammetry at disc electrodes of any size.

Kenji et al. [20] developed a cyclic voltammetric simulation that can be applied to an electrochemically mediated enzyme reaction involving any substrate and mediator concentration. Rajendran et al. [21] reported an analytical expression of transient and steady-state catalytic current of homogeneous mediated bioelectrocatalysis for ping-pong mechanism for semi finite domain.

Kenji et al. [22] developed an electrochemically mediated enzyme reaction involving any substrate and mediator concentrations from cyclic voltammetry simulation for reversible electrochemical reactions with one electron followed by an enzyme reaction with two electrons. To the best of our knowledge, no rigorous analytical expressions for non-steady state concentrations and current with a constant potential for all values of parameters have been previously reported. In this manuscript, we present for the first time the approximate analytical expressions for the concentration of mediator using homotopy perturbation method. The current for constant potential was determined corresponding to all possible values of the parameters.

\section{Mathematical formulation}

\subsection{Reversible reaction coupled with a homogeneous enzyme reaction}

We first, consider an electrochemical reaction coupled with a homogenous enzyme reaction. In equation 1 , we assume one electron transfer for the electrochemical reaction and in equation 2, two electron transfers for the enzyme reactions as shown below:

$$
\begin{array}{ll}
R \leftrightarrow O+e^{-} & \text {(electrochemical reaction) } \\
2 O+S \rightarrow 2 R+P & \text { (enzyme reaction) }
\end{array}
$$

where $R, O, S$ and $P$ are the reduced and oxidized forms of the mediator, substrate and product respectively. Fig. 1 represents the schematic diagram of the above mediated enzyme reaction mechanism. Reaction (1) represents electrochemical reaction at the electrode surface with 
reversible kinetics and reaction (2) represents the enzyme catalysis by Michaelis-Menten kinetics. Although two molecules of the oxidant $O$ are involved in reaction (2), first-order kinetics in $O$ are assumed [20]. Considering one-dimensional diffusion with coupling of reactions (1) and (2) described by Fick's law leads to the following strongly nonlinear partial differential equations [22]:

$$
\begin{aligned}
& \frac{\partial C_{R}(x, t)}{\partial t}=D_{R} \frac{\partial^{2} C_{R}(x, t)}{\partial x^{2}}+\frac{2 k_{c a t} C_{E}}{\frac{K_{M S}}{C_{S}(x, t)}+\frac{K_{M M}}{C_{o}(x, t)}+1} \\
& \frac{\partial C_{S}(x, t)}{\partial t}=D_{S} \frac{\partial^{2} C_{s}(x, t)}{\partial x^{2}}-\frac{k_{c a t} C_{E}}{\frac{K_{M S}}{C_{S}(x, t)}+\frac{K_{M M}}{C_{o}(x, t)}+1}, t>0,0<x<\infty
\end{aligned}
$$

where $C_{R}(x, t), C_{o}(x, t)$ and $C_{s}(x, t)$ represents the reduced and oxidized forms of the mediator and substrate concentration respectively. $k_{\text {cat }}$ is the turnover number. $K_{M M}$ and $K_{M S}$ are the MichaelisMenten constants for the mediator and substrate respectively. $C_{E}$ is the enzyme concentration. $D_{R}$ and $D_{S}$ represents the diffusion coefficients for the reduced form of the mediator and substrate. The initial and boundary conditions for the above equations are given as follows:

$$
\begin{aligned}
& C_{R}=C_{R}^{\infty}, C_{S}=C_{S}^{\infty} \text { when } t=0, x \geq 0 \text { and } t>0, x \rightarrow \infty \\
& C_{R}=C_{R}^{\infty}\left[1+e^{\eta}\right]^{-1},\left(\frac{\partial C_{S}}{\partial x}\right)=0 \text { when } t>0, x=0
\end{aligned}
$$

where $\eta=\left\{\frac{n_{e} F}{R T}\left(E-E^{0}\right)\right\}$ and $C_{R}{ }^{\infty}$ and $C_{S}{ }^{\infty}$ are the bulk concentration of mediator and substrate respectively. Here we can assume that the scan rate is very small and the concentration at $x=0$ is potential dependent. At all $x$ and $t$, sum of the concentrations of reduced and oxidized form of the mediator is constant $\left(C_{R}^{\infty}\right)$.

$$
C_{R}(x, t)+C_{o}(x, t)=C_{R}^{\infty}
$$

The current density $j\left(\mu \mathrm{A} / \mathrm{cm}^{2}\right)$ is given by

$$
j=n_{e} F D_{R}\left(\frac{\partial C_{R}}{\partial x}\right)_{X=0}
$$

By using Eqn. (7), we can rewrite the Eqn. (3) as 


$$
\frac{\partial C_{o}(x, t)}{\partial t}=D_{R} \frac{\partial^{2} C_{o}(x, t)}{\partial x^{2}}-\frac{2 k_{c a t} C_{E}}{\frac{K_{M S}}{C_{s}(x, t)}+\frac{K_{M M}}{C_{o}(x, t)}+1}
$$

Now the initial and boundary conditions for the Eqns. (4) and (9) becomes as follows:

$$
\begin{aligned}
& C_{o}=0, C_{S}=C_{S}^{\infty} \text { when } t=0, x \geq 0 \text { and } t>0, x \rightarrow \infty \\
& C_{o}=\left(\frac{e^{\eta}}{1+e^{\eta}}\right) C_{R}^{\infty},\left(\frac{\partial C_{S}}{\partial x}\right)_{x=0}=0 \text { when } t>0, x=0
\end{aligned}
$$

Now the current density (Eqn. (8)) becomes [21]

$$
j=-n_{e} F D_{R}\left(\frac{\partial C_{o}}{\partial x}\right)_{x=0}
$$

Using a recent approach of homotopy perturbation method [23-25] and shifting formula of Danckwerts' expression [26-28] (Appendix-A), we can obtain the approximate analytical expression for the concentration of mediator:

$$
\frac{C_{o}}{C_{R}^{\infty}}=u(X, \tau)=-\frac{a}{2}\left\{\begin{array}{l}
e^{-\sqrt{\alpha^{\prime}} X}\left[\operatorname{erf}\left(\frac{X-2 \tau \sqrt{\alpha^{\prime}}}{2 \sqrt{\tau}}\right)+1\right]+e^{\sqrt{\alpha^{\prime} X}}\left[\operatorname{erf}\left(\frac{X+2 \tau \sqrt{\alpha^{\prime}}}{2 \sqrt{\tau}}\right)-1\right] \\
-2 e^{-\tau \alpha^{\prime}} \operatorname{erf}\left(\frac{X}{2 \sqrt{\tau}}\right)+2 e^{-\tau \alpha^{\prime}}-2 e^{-\sqrt{\alpha^{\prime}} X}
\end{array}\right\}+a e^{-\alpha^{\prime} \tau} \operatorname{erfc}\left(\frac{X}{2 \sqrt{\tau}}\right)
$$

where the dimensionless parameters

$$
\begin{aligned}
& a=e^{\eta} /\left(1+e^{\eta}\right), \alpha^{\prime}=[1 /(\beta a+\gamma+a)], \alpha_{1}=2 k_{c a t} C_{E} / C_{R}^{\infty}, X=x \sqrt{\alpha_{1} / D_{R}}, \tau=\alpha_{1} t, \\
& \beta=\frac{K_{M S}}{C_{S}^{\infty}}, \gamma=\frac{K_{M M}}{C_{R}^{\infty}}
\end{aligned}
$$

Above Eqn. (13) satisfies the boundary condition (10) and (11) when $\tau$ is very small.

Therefore, the dimensionless current density becomes

$$
\psi=\frac{j}{n_{e} F C_{R}^{\infty} \sqrt{\alpha_{1} D_{R}}}=a\left[\sqrt{\alpha^{\prime}} \operatorname{erf}\left(\sqrt{\alpha^{\prime} \tau}\right)+\frac{e^{-\alpha^{\prime} \cdot \tau}}{\sqrt{\pi \tau}}\right]
$$


The Eqns. (13) and (15) are the new expression for mediator and current correspond to a constant potential for semi infinite boundary conditions. The current density for steady state condition $(\tau \rightarrow \infty)$ becomes

$\psi_{\text {ss }}=a \sqrt{\alpha^{\prime}}$

When $K_{M S}$ or $K_{M M}$ are very large ( $\beta$ or $\gamma$ is large) $\alpha^{\prime}=0$. In this case $\psi=a / \sqrt{\pi \tau}$. This is represented by the Cottrell equation of current for planar electrode.

\subsection{Limiting cases}

Case (i): Homogenous system in the presence of excess amount of substrate and low mediator concentration

If the substrate concentration is extremely high and the mediator concentration is extremely low then Eqn. (3) becomes as follows [22]:

$$
\frac{\partial C_{R}(x, t)}{\partial t}=D_{R} \frac{\partial^{2} C_{R}(x, t)}{\partial x^{2}}+\frac{2 k_{c a t} C_{E} C_{o}(x, t)}{K_{M M}}
$$

Then dimensionless form of Eqn. (17) is as follows:

$\frac{\partial u}{\partial \tau}=\frac{\partial^{2} u}{\partial X^{2}}-\alpha_{1}{ }^{\prime} u$

where $\alpha_{1}{ }^{\prime}=[1 / \gamma]$ is the dimensionless parameter. We obtain the approximate analytical expression of mediator concentration and the current density with enzyme reaction, by replacing $\alpha^{\prime}$ as $\alpha_{1}^{\prime}$ in the Eqns. (15) and (16). Now, the dimensionless current density becomes:

$$
\psi=a\left[(\gamma)^{-1 / 2} \operatorname{erf}\left(\sqrt{(\gamma)^{-1} \tau}\right)+\frac{e^{-. \tau / \gamma}}{\sqrt{\pi \tau}}\right]
$$

The steady state current density becomes:

$$
\psi_{s s}=a(\gamma)^{-1 / 2}
$$

when $\tau$ is small,

$$
\frac{\psi}{\psi_{s s}}=\left(\sqrt{\frac{\gamma}{\pi}}\right) \frac{1}{\sqrt{\tau}}
$$

By plotting $\left(\psi / \psi_{s s}\right)$ verses $(1 / \sqrt{\tau})$ we obtain the kinetic parameter $\gamma\left(=K_{M M} / C_{R}^{\infty}\right)$. 
Case (ii): Homogenous system in the presence of excess amount of substrate when the mediator is confined in bulk phase [22].

If the substrate concentration is extremely high, then the Eqn. (3) is written as: [22]

$$
\frac{\partial C_{o}(x, t)}{\partial t}=D_{R} \frac{\partial^{2} C_{o}(x, t)}{\partial x^{2}}-\frac{2 k_{c a t} C_{E} C_{o}(x, t)}{\left(K_{M M}+C_{o}(x, t)\right)}
$$

Then the dimensionless form of the above Eqn. (22) is as follows:

$\frac{\partial u}{\partial \tau}=\frac{\partial^{2} u}{\partial X^{2}}-\frac{u}{\gamma+u}$

where $\alpha_{2}^{\prime}=[1 /(\gamma+a)]$ is dimensionless parameter. We obtained the approximate analytical expression of mediator concentration and the current density for without enzyme reaction, by replacing $\alpha^{\prime}$ as $\alpha_{2}{ }^{\prime}$ in the Eqns. (15) and (16).The current density for this case becomes:

$$
\psi=a\left[(\gamma+a)^{-1 / 2} \operatorname{erf}\left(\sqrt{(\gamma+a)^{-1} \tau}\right)+\frac{e^{-(\gamma+a)} \tau}{\sqrt{\pi \tau}}\right]
$$

The steady state current density becomes:

$\psi_{S S}=a(\gamma+a)^{-1 / 2}$

From the Eqn. (24) - (25) we also get $\left(\psi / \psi_{s s}\right)$ as

$$
\frac{\psi}{\psi_{s s}}=\sqrt{\gamma+a}\left[\frac{1}{\sqrt{\gamma+a}} \operatorname{erf}\left(\sqrt{\frac{\tau}{\gamma+a}}\right)+\frac{e^{-\tau /(\gamma+a)}}{\sqrt{\pi \tau}}\right]
$$

\section{Determination of kinetic parameters of the enzyme reaction from current density profile}

A simple and closed-form of an analytical expression for the current density (Eqn.(15)) leads to find the rate constant and Michaelis - Menten constants. The current density is dependent upon the parameters $a, \alpha^{\prime}, \alpha_{1}^{\prime}$ and $\alpha_{2}^{\prime}$. Then the Eqn. (15) can be rewritten as:

$$
\left[\frac{j}{n_{e} F C_{R}^{\infty} a}\right]^{2}=D_{R} \alpha_{1} \alpha^{\prime}
$$

Substituting the value of $\alpha_{1}$ and $\alpha^{\prime}$ in the above equation (27), we can obtain the linear equation as: 
$\frac{2 a D_{R} C_{E}}{C_{R}^{\infty}}\left[\frac{j}{n_{e} F C_{R}^{\infty}}\right]^{-2}=\left[\frac{K_{M M}}{C_{R}^{\infty} k_{c a t}}\right] \frac{1}{a}+\left[\frac{K_{M S}}{k_{c a t} C_{S}^{\infty}}+\frac{1}{k_{c a t}}\right]$

The plot of $\frac{2 a D_{R} C_{E}}{C_{R}^{\infty}}\left[\frac{j}{n_{e} F C_{R}^{\infty}}\right]^{-2}$ versus $\frac{1}{a}$ gives the slope $=\left[\frac{K_{M M}}{C_{R}^{\infty} k_{\text {cat }}}\right]$ and intercept $\left(C_{1}\right)=$ $\left[\frac{K_{M S}}{k_{c a t} C_{S}^{\infty}}+\frac{1}{k_{c a t}}\right]$ as shown in Fig.2(a). Now, using the plot of the parameter $\left(C_{1}\right)$ versus $\left[\frac{1}{C_{S}^{\infty}}\right]$, we can estimate the Michaelis-Menten constant for the substrate $K_{M S}$ and mediator $K_{M M}$, turnover rate $k_{\text {cat }}$ (Fig. 2(b)) . The flowchart for estimation of rate constants from the Eqn. (27) is also given in Fig. 3. The graphical procedure yields the Michaelis-Menten constants $K_{M S}=1 \mathrm{mM}$, $K_{M M}=1 \mathrm{mM}, k_{\text {cat }}=5 \mathrm{mM} / \mathrm{s}, C_{\mathrm{S}}^{\infty}=10 \mathrm{mM}$ and $C_{R}^{\infty}=10 \mathrm{mM}$.

\section{Determination of diffusion layer thickness}

An estimate can be made of the diffusion layer thickness $\delta$, [28] by using the following equation:

$\frac{j}{n_{e} F}=\frac{D_{R} C_{R}^{\infty}}{\delta}\left[1-\frac{C_{O}(x=0)}{C_{R}^{\infty}}\right]$

By substituting Eqn.(15) in Eqn.(29), we can obtain the Eqn. (30) as follows:

$$
\frac{D_{R}}{\delta}\left[1-\frac{C_{o}(x=0)}{C_{R}^{\infty}}\right]=C_{R}^{\infty} a \sqrt{D_{R} \alpha_{1}}\left[\sqrt{\alpha^{\prime}} \operatorname{erf}\left(\sqrt{\alpha^{\prime} \tau}\right)+\left(\frac{e^{-\alpha^{\prime} \cdot \tau}}{\sqrt{\pi \tau}}\right)\right]
$$

From the above Eqn. (30), the dimensionless diffusion layer thickness $\delta(\tau)$ can be determined as given below:

$\delta=\frac{(1-a)}{a} \sqrt{\frac{D_{R}}{\alpha_{1}}}\left\{\left[\sqrt{\alpha^{\prime}} \operatorname{erf}\left(\sqrt{\alpha^{\prime} \tau}\right)+\left(\frac{e^{-\alpha^{\prime} \cdot \tau}}{\sqrt{\pi \tau}}\right)\right]\right\}^{-1}$

From Eqn. (31), we can also obtained the mass transfer coefficient $\left(D_{R} / \delta\right)$.

\section{Validation of the model}

Next, we present how the analytical model is validated against the simulation results. Our analytical expression of concentrations of mediator is compared with simulation results in Tables 
1(a-b) and Fig. 4 for non-steady state conditions. Matlab/Scilab program is also given in Appendix $\mathrm{B}$ as a supplementary material. From these tables, it can be noticed that our analytical results matches quite well with the numerical results for various values of time $\tau$ and potential $\eta$, provided $\beta \leq \gamma$. The concentration of mediator attains the steady-state value when time $\tau=100$. Our approximate analytical expression for current density (Eqn.(15)) is also compared with the limiting case results in Fig.5.

\section{Discussion}

Eqns. (13) and (15) represent the new closed approximate analytical expression of the non steady-state concentration of mediator and current for all values of parameters. The current density depends upon the parameters such as dimensionless potential, oxidized form of bulk mediator concentration and Michaleis-Menten constant for the mediator. Fig. 4. illustrates dimensionless concentration of oxidized mediator versus dimensionless distance from the electrode surface using Eqn. (13) for various values of the parameters. Oxidised form of the mediator generated at the electrode is consumed within the diffusion layer by reaction with the reduced form of the enzyme present at its bulk concentration.

From the figures, it is also observed that the concentration of mediator in the vicinity of the electrode surface increase when potential increases. This is also due to depletion of the substrate concentration in the vicinity of electrode when there is a high enzyme activity and mediator concentration and low substrate concentration. Dimensionless current density (Eqn. (15)) is compared with the limiting cases results ( Eqns. (19) and (24)) in Fig.5. Satisfactory agreement is noted between analytical results and simulation results is $3.567 \%$.

\subsection{Influence of the electrode potential, reduced concentration of mediator on the current}

The influence of the current density versus dimensionless potential for various values of parameters $\beta, \gamma$ and $\tau$ is shown in Figs. 6(a-c). From this figure, it is observed that, the current density reaches the peak value when potential $\eta \geq 4$ for all values of the other parameters. Also the current density decreases when dimensionless Michaelis-Menten constants for substrate $(\beta)$, mediator $(\gamma)$ and time $(\tau)$ increases. From the Figs. 6, it is also noted that the shape of the cyclic 
voltammograms changes significantly with enzyme $\left(\alpha_{1}\right)$, substrate $\left(C_{S}^{\infty}\right)$ and mediator $\left(C_{R}^{\infty}\right)$ concentrations. At higher substrate concentration, the catalytic current density reaches the maximum value.

\subsection{Influence turnover, Michalis-Menten constant for the mediator and substrate on the current}

Fig.6 (a-c) illustrates the dimensionless current density versus potential for various values of the parameters. The current density increases as the dimensionless parameters decreases. From Fig. 6(d), it is inferred that the current density increases as the dimensionless potential increase.

\subsection{Influence of diffusion layer thickness on the current}

Increasing the velocity of the solution brings reactants up to the electrode surface more easily, thus reducing the thickness of the diffusion layer $(\delta)$. As $\delta$ decreases, the value of the limiting diffusion current density will increase, as per Eqn. (29). The diffusion-layer thickness is the only factor influencing the limiting current density, which corresponds to the results of current transients indicated in Fig. 9.

Diffusion layer thickness is plotted against the potential as shown in Fig.9 (a-d). The figure demonstrates that the diffusion layer thickness depends on the parameters bulk concentration of substrate and mediator, turnover number and time. When the bulk concentration of substrate or mediator increases the diffusion layer thickness is increases. The diffusion layer thickness is increases when the turnover number and time decreases. From the Fig. 9, it is observed that the diffusion layer thickness reaches the steady state value when the potential $\eta=2$ for all values of other parameters. The thickness of the approximately linear diffusion layer grows with time.

\section{Differential sensitivity analysis of parameters}

Differential sensitivity analysis is based on partial differentiation of the aggregated model. We have found the partial derivative of current density $\psi$ (dependent variable) with respect to the

parameters $\beta$, $\gamma$ and $\eta$ (independent variables). At some fixed experimental values of the parameters $(\beta=0.05, \gamma=5$ and $\eta=1)$, numerical value of rate of change of current density $\psi$ can be obtained. From this value we can obtain the percentage of change in current density with respect to the parameters $\beta, \gamma$ and $\eta$. Sensitivity analysis of the parameters is given in Fig. 10 . 
From this figure, it is inferred that the potential $(\eta)$ has more impact than the Michalies constant for mediator for the variation of the current density. The remaining parameter Michaelis-Menten constant substrate accounts for only small changes in current density. This result is also confirmed in the Fig. 10.

\section{Conclusion}

A theoretical model for reversible electrochemically mediated enzyme reaction has been described. In this work, systems of coupled, non-steady state nonlinear reaction diffusion equations are solved analytically. We can determine the enzyme kinetic constants from the current density. The influence of the parameters such as diffusion layer thickness, turnover, Michaelis-Menten constant for the mediator and substrate and the electrode potential on the current are also discussed. Sensitivity analysis of the parameters is also reported. This technique can also be extended for any reaction system between any redox enzymes and mediator for quasi reversible reactions.

\section{Nomenclature:}

The nomenclature employed in this manuscript is represented in the table below:

\begin{tabular}{|l|l|l|}
\hline Parameters & Definition & Units \\
\hline$a=e^{\eta} /\left(1+e^{\eta}\right)$ & Dimensionless parameter & $($ none $)$ \\
\hline$C_{E}$ & Enzyme concentration & $(\mathrm{mM})$ \\
\hline$C_{O}$ & Concentration of oxidized mediator & $(\mathrm{mM})$ \\
\hline$C_{R}^{\infty}$ & Bulk concentration of reduced mediator & $(\mathrm{mM})$ \\
\hline$C_{R}$ & Bulk concentration of reduced mediator & $(\mathrm{mM})$ \\
\hline$C_{S}$ & Concentration of substrate & $(\mathrm{mM})$ \\
\hline$C_{s}^{\infty}$ & Bulk concentration of substrate & $(\mathrm{mM})$ \\
\hline$D_{R}, D_{S}, D_{O}$ & Diffusion coefficients & $(\mathrm{cm} / \mathrm{s})$ \\
\hline$K_{M M}$ & Michaelis constants for the mediator & $(\mathrm{mM})$ \\
\hline$K_{M S}$ & Michaelis constants for the substrate & $(\mathrm{mM})$ \\
\hline
\end{tabular}




\begin{tabular}{|l|l|l|}
\hline$k_{\text {cat }}$ & Turnover number & $(1 / \mathrm{s})$ \\
\hline$r=\left(D_{S} / D_{R}\right)$ & Dimensionless parameter & $($ none $)$ \\
\hline $\mathrm{T}$ & Time & $(\mathrm{s})$ \\
\hline$u=\left(C_{o} / C_{R}^{\infty}\right)$ & Dimensionless concentration of oxidized mediator & $($ none) \\
\hline$v=\left(C_{s} / C_{s}^{\infty}\right)$ & Dimensionless concentration of substrate & (none) \\
\hline$x$ & Distance from electrode & (cm) \\
\hline$X=x \sqrt{\alpha_{1} / D_{R}}$ & Dimensionless distance from the electrode & (none) \\
\hline$\alpha=\left(K_{M S} / C_{S}^{\infty}\right)$ & Dimensionless parameter & (none) \\
\hline$\alpha_{1}=\left(2 k_{c a t} C_{E} / C_{R}^{\infty}\right)$ & Dimensionless parameter & $(1 / \mathrm{s})$ \\
\hline$\beta=\left(K_{M S} / C_{R}^{\infty}\right)$ & $\begin{array}{l}\text { Dimensionless Michaelis constants for the } \\
\text { substrate }\end{array}$ & (none) \\
\hline$\beta_{1}=\left(k_{c a t} C_{E}\right) / C_{R}^{\infty}$ & Dimensionless parameter & $(1 / \mathrm{s})$ \\
\hline$\gamma=\frac{K_{M M}}{C_{R}^{\infty}}$ & $\begin{array}{l}\text { Dimensionless Michaelis constants for the } \\
\text { mediator }\end{array}$ & (none) \\
\hline$\eta=\frac{n_{e} F\left(E-E^{0}\right)}{R T}$ & Dimensionless potential & (none) \\
\hline$\tau=\alpha_{1} t$ & Dimensionless time & (none) \\
\hline
\end{tabular}

\section{References}

[1] R.S. Nicholson, I. Shain, Theory of stationary electrode polarography. Single scan and cyclic methods applied to reversible, irreversible, and kinetic systems, Anal.Chem. 36 (1964) 706723.

[2] J. K. Leypoldt, D. A. Gough, Model of a two-substrate enzyme electrod for glucose, Anal. Chem. 56 (1984) 2896-2904.

[3] P. N. Bartlett, R.G. Whitaker, Electrochemical immobilisation of enzymes: Part I. Theory J.Electroanal. Chem. 224 (1987) 27-35.

[4] P. N. Bartlett, R. G. Whitaker, Electrochemical immobilisation of enzymes: Part II. Glucose oxidase immobilised in poly-N-methylpyrrole J. Electroanal. Chem. 224 (1987) 37-48. 
[5] J. F. Rusling, K. Ito, Voltammetric determination of electron-transfer rate between an enzyme and a mediator, Anal. Chim. Acta 252 (1991) 23-27.

[6] P.N. Bartlett, K.F.E. Pratt, Modeling of processes in enzyme electrodes, Biosens. Bioelectron. 8 (1993) 451-462.

[7] D. Britz, Digital Simulation in Electrochemistry, $2^{\text {nd }}$ ed.; Springer-Verlag:Berlin,1988.

[8] L. D. Mell, J. T. Maloy, A model for the amperometric enzyme electrode obtained through digital simulation and applied to the immobilized glucose oxidase system. Anal. Chem. 47 (1975) 299-307.

[9] A. Bergel, M. Comtat, Theoretical evaluation of transient responses of an amperometric enzyme electrode, Anal. Chem. 56 (1984) 2904-2909.

[10] J.Y. Lucisano, D.A. Gough, Transient response of the two-dimensional glucose sensor Anal. Chem. 60 (1988) 1272-1281.

[11] F. Battaglini, E.J. Calvo, Digital-simulation of homogeneous enzyme-kinetics for amperometric redox-enzyme electrodes. Anal. Chim. Acta 258 (1992) 151-160.

[12] N. Martens, E.A.H. Hall, Model for an immobilized oxidase enzyme electrode in the presence of two oxidants, Anal. Chem. 66 (1994) 2763-2770.

[13] M.H. Osman, A.A. Shah, R.G.A. Wills, F.C. Walsh, Mathematical modelling of an enzymatic fuel cell with an air-breathing cathode , ElectrochimicaActa, 112 (2013) 386-393.

[14] T.Q.N. Do, M. Varničić, R. Hanke-Rauschenbach, T. Vidaković-Koch, K. Sundmacher, Mathematical modeling of a porous enzymatic electrode with direct electron transfer mechanism, ElectrochimicaActa, 137 (2014) 616-626.

[15] C. Picioreanu, I. M. Head, K.P. Katuri, M.C.M. van Loosdrecht, K. Scott, A computational model for biofilm-based microbial fuel cells, Water Research, 41 (2007) 2921-2940.

[16] A. Eswari, L. Rajendran, Mathematical modeling of cyclic voltammetry for EC reaction, Russian Journal of Electrochemistry, 47 (2) (2011) 181-190.

[17] A. Eswari and L. Rajendran, Mathematical modeling of cyclic voltammetry for $\mathrm{EC}_{2}$ reaction, Russian Journal of Electrochemistry, 47 (2) (2011) 191-199.

[18] S. Eloul, R. G. Compton, Voltammetric sensitivity enhancement by using preconcentration adjacent to the electrode: simulation, critical evaluation, and insights, J. Phys.Chem. C, 118(42) (2014) 24520-24532. 
[19] A.Molina, C. Serna, Q. Li, E. Laborda, C. Batchelor-McAuley, R. G. Compton, Analytical solutions for the study of multielectron transfer processes by staircase, cyclic, and differential voltammetries at disc microelectrodes, J. Phys. Chem. C, 116 (2012) 11470-11479

[20] Y. Kenji, K. Satoshi, K. Yoshihiro, Cyclic voltammetric simulation of electrochemically mediated enzyme reaction and elucidation of biosensor behaviors, Analytical Bioanalytical Chemistry, 372 (2002) 248-253.

[21] L. Rajendran, K. Saravankumar, Analytical expression of transient and steady-state catalytic current of mediated bioelectrocatalysis, Electrochimica Acta, 147 (2014) 678-687.

[22]Y. Kenji, K.Yoshihiro, Cyclic Voltammetric simulation for electrochemically mediated enzyme reaction and determination of enzyme kinetic constants, Analytical Chemistry, 70 (1998) 3368-3376.

[23] J.H. He, L.F. Mo, Comments on "Analytical solution of amperometric enzymatic reactions based on Homotopy perturbation method”, Electro. Chim. Acta 102 (2013) 472.

[24] L. Rajendran, S. Anitha, Reply to "Comments on analytical solution of amperometric enzymatic reactions based on Homotopy perturbation method," by Ji-Huan He, Lu-Feng Mo [Electrochim. Acta (2013)], Electro. Chim. Acta 102 (2013) 474.

[25] O.M. Kirthiga, L. Rajendran, Approximate analytical solution for non-linear reaction diffusion equations in a mono-enzymatic biosensor involving Michaelis-Menten kinetics, $J$. Electroanal Chem, 751 (2015) 119-127.

[26] P.V. Danckwerts, Absorption by simultaneous diffusion and chemical reaction into particles of various shapes and into falling drops, Trans Faraday Soc., 47 (1951) 1014.

[27] G. Rahamathunissa, C.A. Basha, L. Rajendran, The theory of reaction-diffusion processes at cylindrical ultramicroelectrodes, J. Theor. Comput. Chem 6 (2) (2007) 301-307.

[28] M. Rasi, L. Rajendran, M. V. Sangaranarayanan,Enzyme-catalyzed oxygen reduction reaction in biofuel cells:analytical expressions for chronoamperometric current densities, $J$. Electrochem Soc, 162 (9) H671-H680 (2015) 


\section{Appendix A: Non linear dimensionless form}

Eqns. (4) and (9) can be written as given below:

$$
\begin{aligned}
& \frac{\partial C_{s}(x, t)}{\partial t}=D_{S} \frac{\partial^{2} C_{s}(x, t)}{\partial x^{2}}-\frac{k_{c a t} C_{E}}{\frac{K_{M S}}{C_{s}(x, t)}+\frac{K_{M M}}{C_{o}(x, t)}+1}, t>0,0<x<\infty \\
& \frac{\partial C_{o}(x, t)}{\partial t}=D_{R} \frac{\partial^{2} C_{o}(x, t)}{\partial x^{2}}-\frac{2 k_{c a t} C_{E}}{\frac{K_{M S}}{C_{S}(x, t)}+\frac{K_{M M}}{C_{o}(x, t)}+1}
\end{aligned}
$$

The nonlinear partial differential equation (A1) are made dimensionless by defining the following dimensionless parameters:

$$
\begin{aligned}
& u=\frac{C_{o}}{C_{R}^{\infty}}, v=\frac{C_{S}}{C_{S}^{\infty}}, \tau=\alpha_{1} t, \quad X=x \sqrt{\frac{\alpha_{1}}{D_{R}}}, \quad r=\frac{D_{S}}{D_{R}}, \quad \alpha_{1}=\frac{2 k_{c a t} C_{E}}{C_{R}^{\infty}}, \beta=\frac{K_{M S}}{C_{S}^{\infty}}, \\
& \gamma=\frac{K_{M M}}{C_{R}^{\infty}}, \quad a=\frac{e^{\eta}}{1+e^{\eta}}, \quad \beta_{1}=\frac{C_{R}^{\infty}}{2 C_{S}^{\infty}}
\end{aligned}
$$

The governing nonlinear reaction diffusion Eqns. (A1) can be expressed as non dimensional form as follows:

$$
\begin{aligned}
& \frac{\partial u}{\partial \tau}=\frac{\partial^{2} u}{\partial X^{2}}-\frac{u v}{(\beta u+\gamma v+u v)} \\
& \frac{\partial v}{\partial \tau}=r \frac{\partial^{2} v}{\partial X^{2}}-\frac{\beta_{1} u v}{(\beta u+\gamma v+u v)}
\end{aligned}
$$

where $u$ and $v$ represent a normalized concentration of mediator and substrate respectively. $\mathrm{X}$ is the normalized distance from the electrode. $\beta, \gamma$ and $\beta_{1}$ are the normalized kinetic parameters. The initial and boundary conditions in dimensionless form becomes as follows:

$$
\begin{aligned}
& u=0, v=1 \text { when } \tau=0, X \geq 0 \text { and } \tau>0, X \rightarrow \infty \\
& u=a,\left(\frac{\partial v}{\partial X}\right)=0 \text { when } \tau>0, X=0
\end{aligned}
$$

Now the dimensionless current density becomes

$$
\psi=\frac{j}{n_{e} F C_{R}^{\infty} \sqrt{\alpha_{1} D_{R}}}=-\left(\frac{\partial u}{\partial X}\right)_{X=0}
$$


A general relationship, arising from Danckwerts' expression, allows the computation of the transient concentration/limiting current in a system with a homogeneous first-order reaction regenerating the electroactive species with diffusion and convection, from the concentration/limiting current at the same electrode when there is no homogeneous reaction.

$u(X, \tau)=\alpha_{0}^{\alpha^{\tau}} \int_{0}^{-\alpha^{\prime} p} u_{0}(X, \tau) d p+e^{-\alpha^{\prime} \tau} u_{0}(X, \tau)$

where $\alpha^{\prime}=[1 /(\beta a+\gamma+a)]$ is a dimensionless parameter. Here, $u_{0}(X, \tau)$ is the concentration of mediator without homogeneous term. The normalized concentration and current density becomes $u_{0}(X, \tau)=\operatorname{erfc}(X /(2 \sqrt{\tau}))$ and $(1 / \sqrt{\pi \tau})$. Using this result and shifting formula of Danckwerts' expression, we can obtain the concentration of mediator $u(X, \tau)$ as follows:

$$
\frac{C_{O}}{C_{R}^{\infty}}=u(X, \tau)=\alpha^{\prime} a \int_{0}^{\tau} e^{-\alpha^{\prime} p} \operatorname{erfc}\left(\frac{X}{2 \sqrt{p}}\right) d p+a e^{-\alpha^{\prime} \tau} \operatorname{erfc}\left(\frac{X}{2 \sqrt{\tau}}\right)
$$

Integrating the above equation we get the equation (13) in the text.

\section{Appendix B: Homogeneous mediated bioelectrocatalysis in ping-pong mechanism of the oxidoreductases (semi finite)}

For this finite case, the nonlinear reaction diffusion equations (3) and (4) can be written in the form as Eqn. (B1) and (B2):

$$
\begin{gathered}
\frac{\partial C_{o}(x, t)}{\partial t}=D_{R} \frac{\partial^{2} C_{o}(x, t)}{\partial x^{2}}-\frac{2 k_{c a t} C_{E}}{\frac{K_{M S}}{C_{s}(x, t)}+\frac{K_{M M}}{C_{o}(x, t)}+1} \\
\frac{\partial C_{s}(x, t)}{\partial t}=D_{S} \frac{\partial^{2} C_{s}(x, t)}{\partial x^{2}}-\frac{k_{c a t} C_{E}}{\frac{K_{M S}}{C_{s}(x, t)}+\frac{K_{M M}}{C_{o}(x, t)}+1}
\end{gathered}
$$

Now the initial and boundary conditions for the Eqns. (B1) - (B2) are

$$
\begin{gathered}
C_{o}=0, C_{s}=C_{s}^{\infty} \text { when } t=0, x \geq 0, \text { and } t>0, x=L \\
C_{O}=\left(\frac{e^{\eta}}{1+e^{\eta}}\right) C_{R}^{\infty},\left(\frac{\partial C_{s}}{\partial x}\right)_{x=0}=0 \text { when } t>0
\end{gathered}
$$


The dimensionless parameter $L=\sqrt{D_{R} / \alpha_{1}}$ is included in the Eqn. (A2). We get the equation as same as Eqns. (A3) and (A4) for the finite case. The initial and boundary conditions for the dimensionless concentration are described as follows:

$$
\begin{aligned}
& u=0, v=1 \text { when } \tau=0, X \geq 0, \text { and } \tau>0, X=1 \\
& u=\frac{e^{\eta}}{1+e^{\eta}}=a,\left(\frac{\partial v}{\partial X}\right)_{X=0}=0 \text { when } \tau>0
\end{aligned}
$$

Using a recent approach of Homotopy pertuberation method, we obtained an approximate analytical expression for the concentration of mediator $u$ and substrate $v$

$$
\begin{aligned}
u(X, t)= & a \frac{\sinh \left(\sqrt{\alpha^{\prime}}(1-X)\right)}{\sinh \left(\sqrt{\alpha^{\prime}}\right)}+2 a \sum_{n=1}^{\infty} \frac{(-1)^{n} n \pi \sin (n \pi(1-X)) e^{-\left(\alpha^{\prime}+n^{2} \pi^{2}\right) t}}{\alpha^{\prime}+n^{2} \pi^{2}} \\
v(X, t)= & \frac{\cosh \left(\sqrt{\left(\beta^{\prime} / r\right)} X\right)}{\left.\cosh \left(\sqrt{\left(\beta^{\prime} / r\right.}\right)\right)}-4 \pi r \sum_{n=0}^{\infty} \frac{(1+2 n)(-1)^{n} \cos ((1+2 n) \pi X / 2) e^{-\left((1+2 n)^{2} \pi^{2} r+4 \beta^{\prime}\right) t / 4}}{\left[4 \beta^{\prime}+(1+2 n)^{2} \pi^{2} r\right]} \\
& +\frac{4}{\pi} \sum_{n=0}^{\infty} \frac{(-1)^{n} \cos ((1+2 n) \pi X / 2) e^{-\left((1+2 n)^{2} \pi^{2} r+4 \beta^{\prime}\right) t / 4}}{(1+2 n)}
\end{aligned}
$$

where $\beta^{\prime}=\beta_{1} a /(\beta a+\gamma+a)$

Therefore the dimensionless current density for finite case is as follows:

$\psi=a\left[\sqrt{\alpha^{\prime}} \operatorname{coth}\left(\sqrt{\alpha^{\prime}}\right)+2 \pi^{2} \sum_{n=1}^{\infty} \frac{n^{2} e^{-\left(\alpha^{\prime}+n^{2} \pi^{2}\right) t}}{\alpha^{\prime}+n^{2} \pi^{2}}\right]$

where $\alpha^{\prime}=[1 /(\beta a+\gamma+a)]$

Rajendran and Saravanakumar [21] obtained the analytical expressions of concentration of mediator and current by solving the Eqn. (B1) for the boundary conditions $\left(\frac{\partial u}{\partial X}\right)_{X=1}=0$ or $\left(\frac{\partial C_{0}}{\partial x}\right)_{x=L}=0$

\section{Appendix C: Matlab/Scilab coding to find the numerical solution of Eqns (A3) and (A4)}

function pdex4 


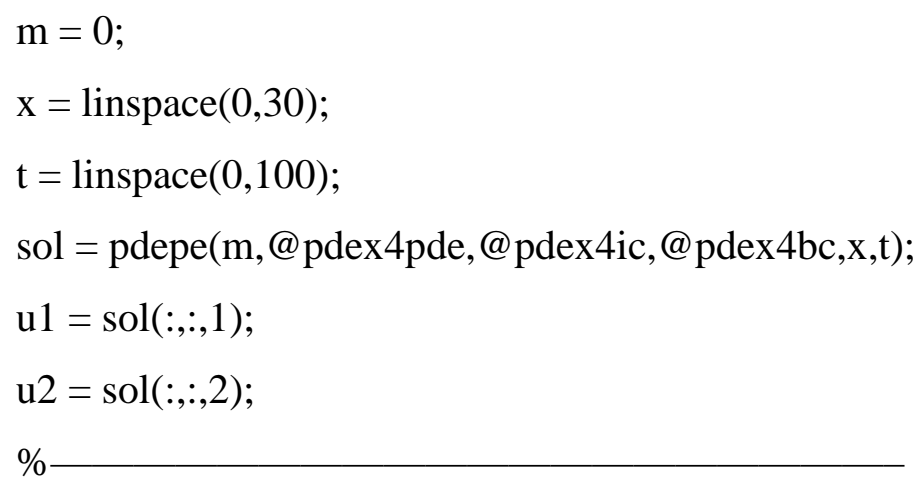

figure

$\operatorname{plot}(\mathrm{x}, \mathrm{u} 1(\mathrm{end}, \mathrm{:}))$

title('u1(x,t)')

xlabel('Distance x')

ylabel('u1(x,1)')

figure

$\operatorname{plot}(\mathrm{x}, \mathrm{u} 2(\mathrm{end}, \mathrm{:}))$

title('u2(x,t)')

xlabel('Distance x')

ylabel('u2(x,2)')

\%-----------

function $[c, f, s]=\operatorname{pdex} 4 p d e(x, t, u, D u D x)$

$\mathrm{C}=[1 ; 1]$;

$\mathrm{f}=[1 ; 1] .^{*} \mathrm{DuDx}$;

beta $=.1$;gamma $=100$; beta $1=1 ; \mathrm{cri}=10$;

$\mathrm{F}=-\left(\mathrm{u}(1) * \mathrm{u}(2) /\left(\left(\right.\right.\right.$ beta $\left.^{*} \mathrm{u}(1)\right)+($ gamma*u(2)) $\left.+(\mathrm{u}(1) * \mathrm{u}(2)))\right)$;

$\mathrm{F} 1=-$ beta $1 *((\mathrm{u}(1)) * \mathrm{u}(2) /(($ beta*$(\mathrm{u}(1)))+($ gamma*u(2)) $+((\mathrm{u}(1)) * \mathrm{u}(2))))$;

$\mathrm{s}=[\mathrm{F} ; \mathrm{F} 1]$;

$\%$

function $\mathrm{u} 0=\operatorname{pdex} 4 \mathrm{ic}(\mathrm{x})$

$\mathrm{u} 0=[0 ; 1]$

function [pl,ql,pr,qr] = pdex4bc(xl,ul,xr,ur,t)

eta $=(2)$;

$\mathrm{pl}=[\mathrm{ul}(1)-(\exp (\mathrm{eta}) /(1+\exp (\mathrm{eta}))) ; 0]$; 


$$
\begin{aligned}
& \mathrm{ql}=[0 ; 1] ; \\
& \mathrm{pr}=[\operatorname{ur}(1)-0 ; \operatorname{ur}(2)-1] ; \\
& \mathrm{qr}=[0 ; 0] ;
\end{aligned}
$$




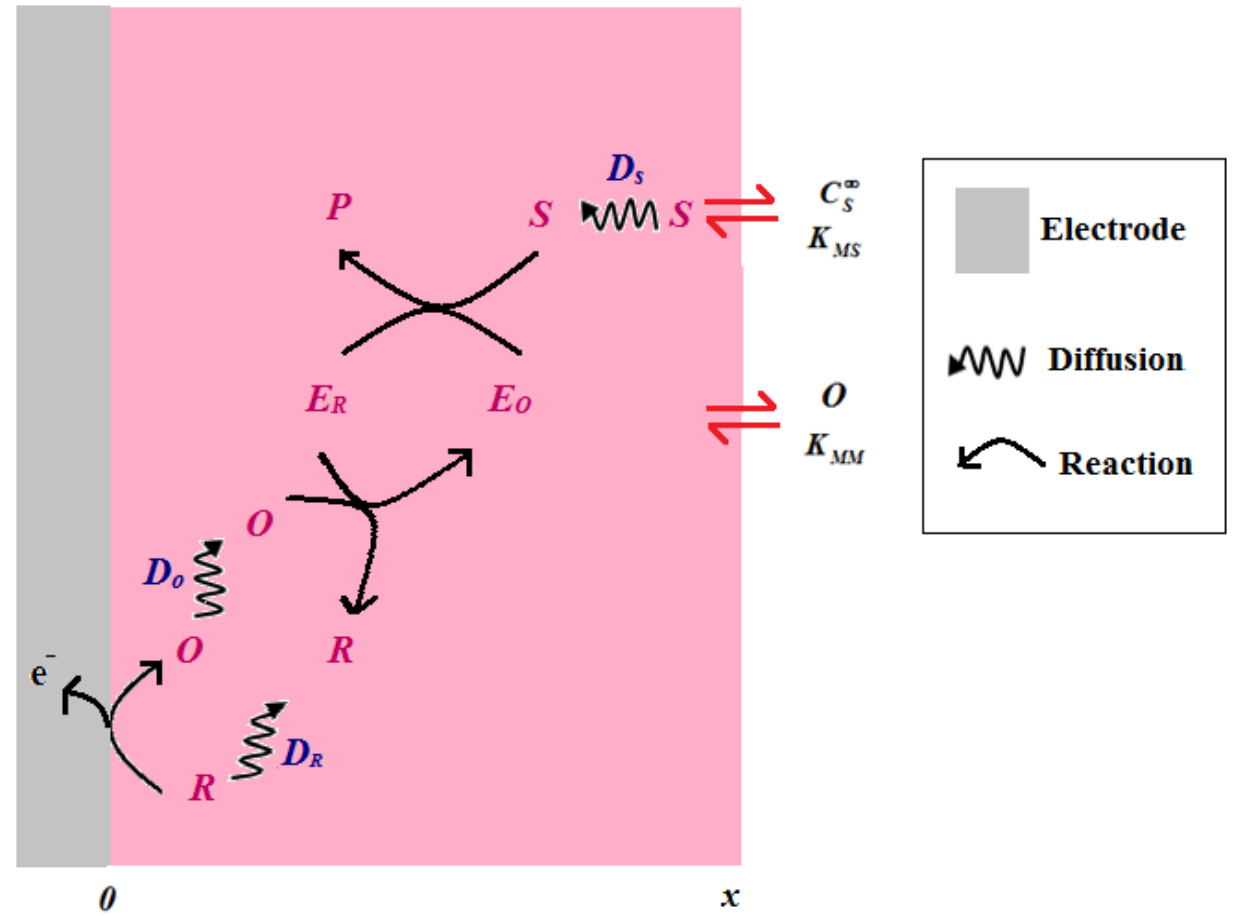

Fig.1. Schematic diagram of mediated enzyme reaction mechanism.
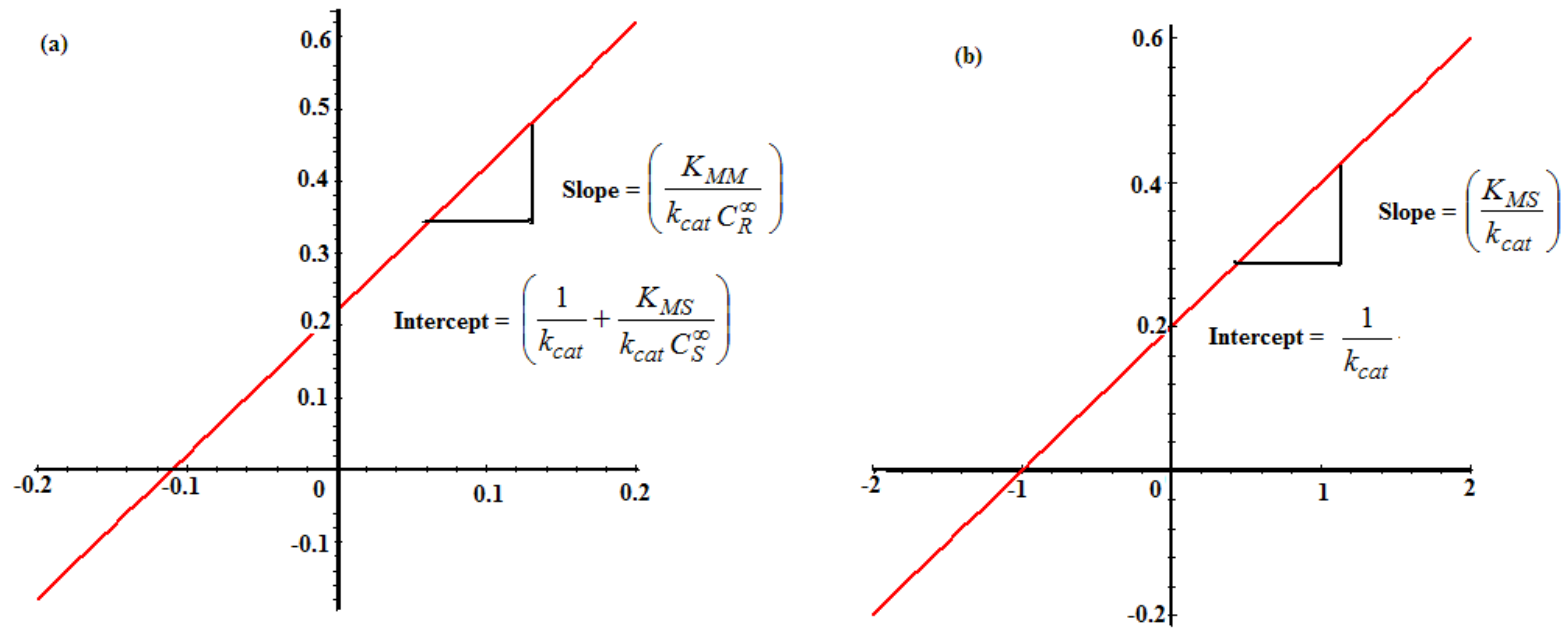

Fig. 2. Determination of kinetics parameters $k_{\text {cat }}, K_{M S}$ and $K_{M M}$ using the Eqn. (27). The graphical procedure yields the Michaelis-Menten constants $K_{M S}=1 \mathrm{mM}, K_{M M}=1 \mathrm{mM}$, $k_{\text {cat }}=5 \mathrm{mM} / \mathrm{s}, C_{S}^{\infty}=10 \mathrm{mM}$ and $C_{R}^{\infty}=10 \mathrm{mM}$. 


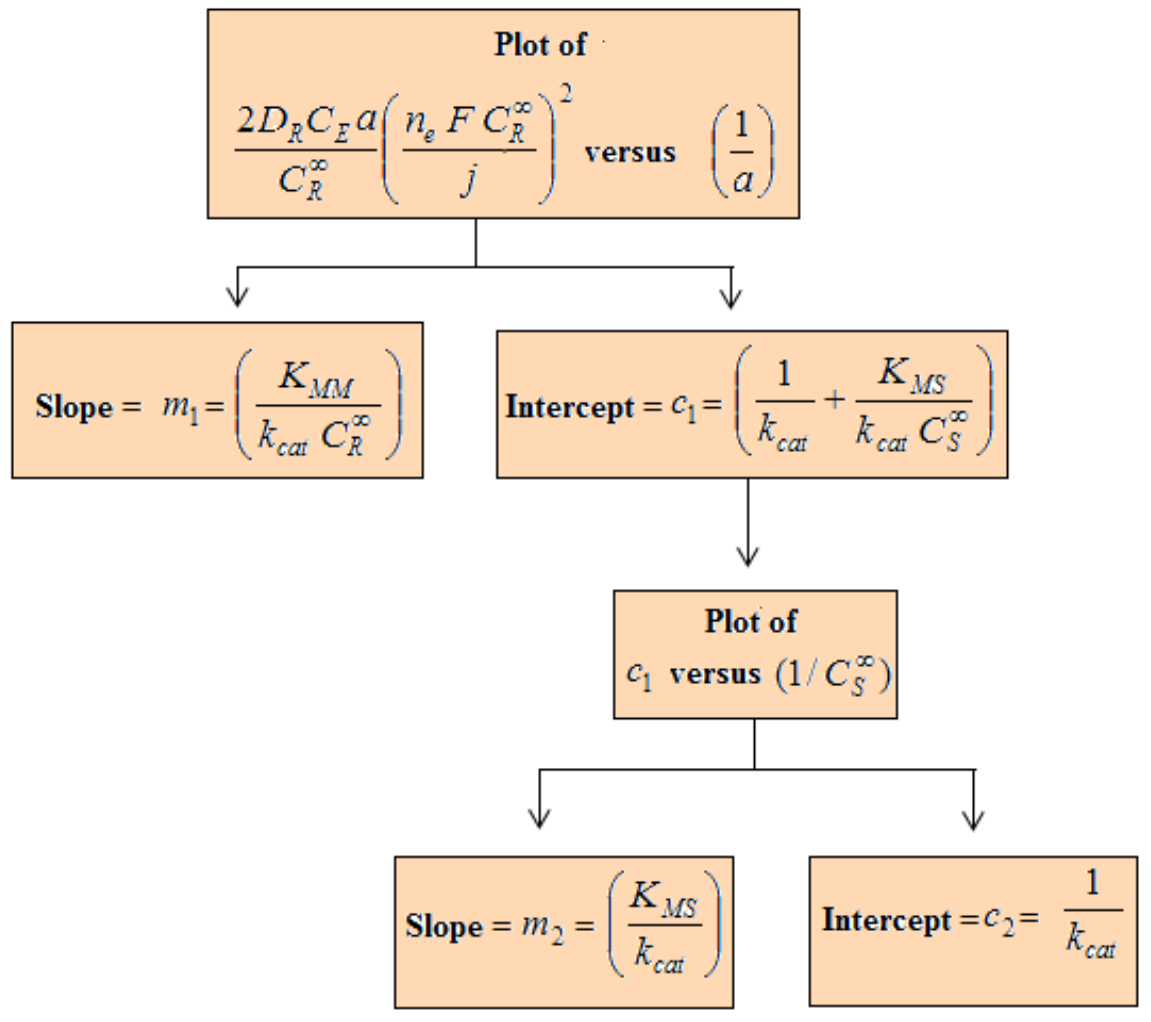

Fig .3.Flowchart for estimation of the rate constant and Michaelis-Menten constants by using the Eqn. (27).
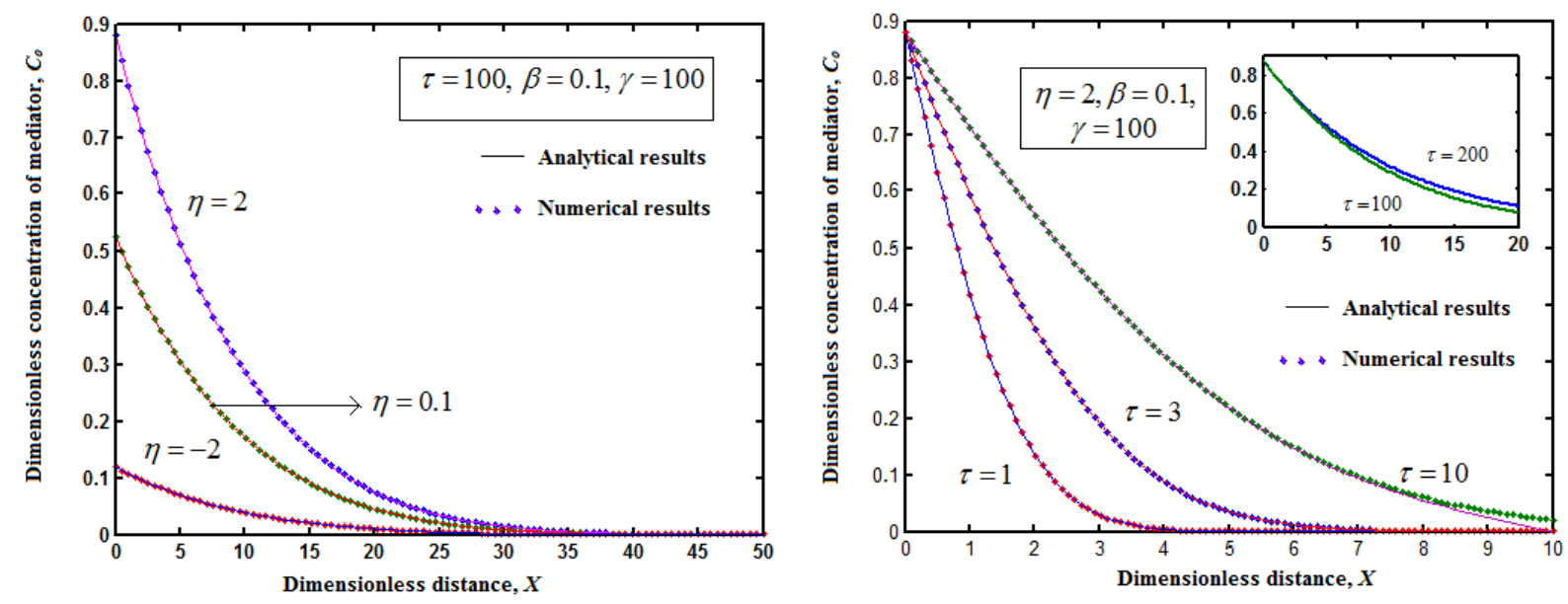

Fig. 4.Plot of dimensionless concentration of oxidized mediator versus dimensionless distance from the electrode using Eqn. (13) for various values of the parameters. 

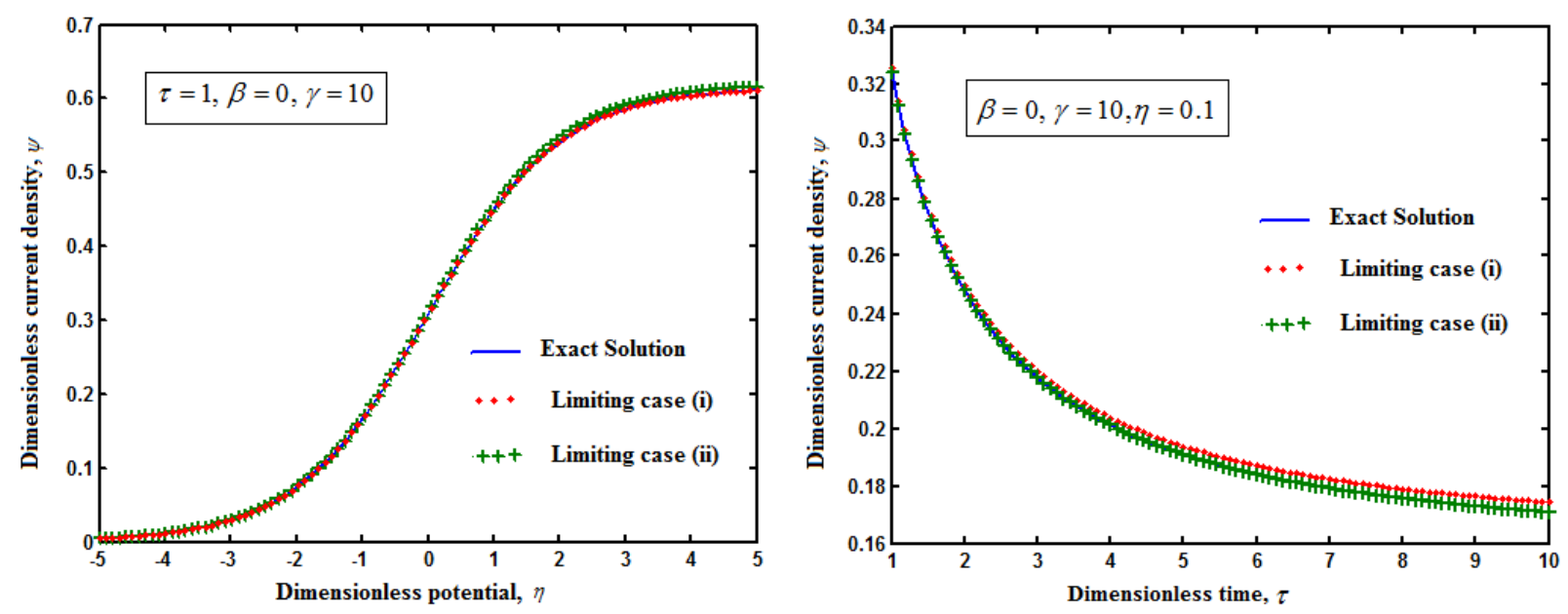

Fig.5. Comparison of dimensionless current density (Eqn. (15) ) with the limiting cases using Eqns. (19) and (24).

(a)

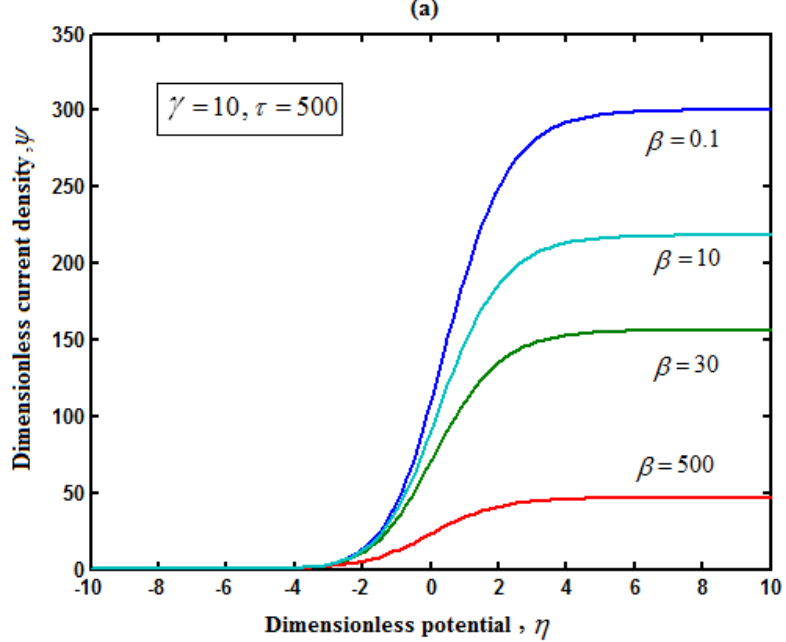

(c)

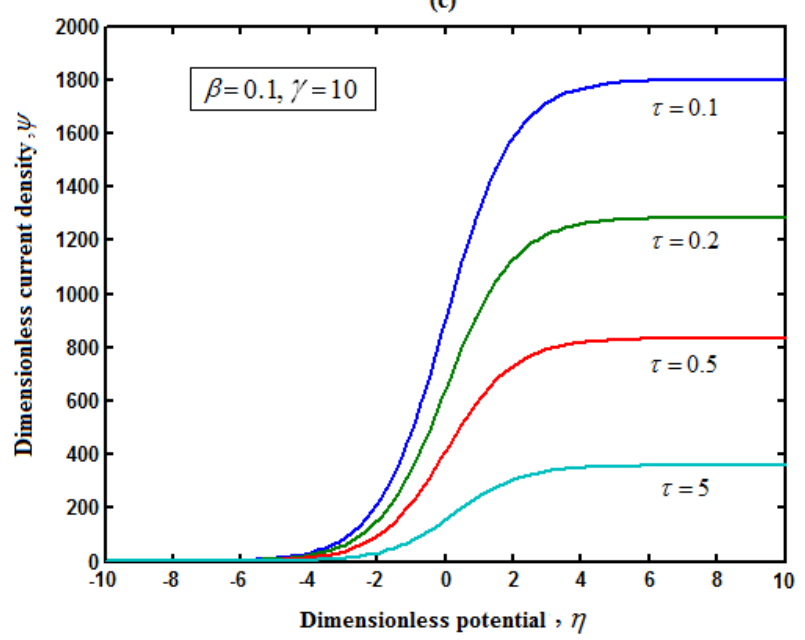

(b)

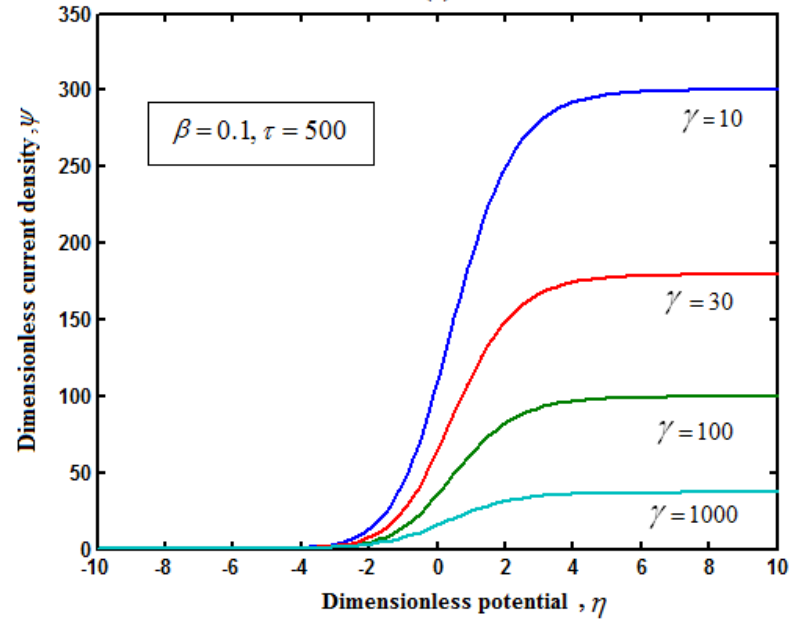

(d)

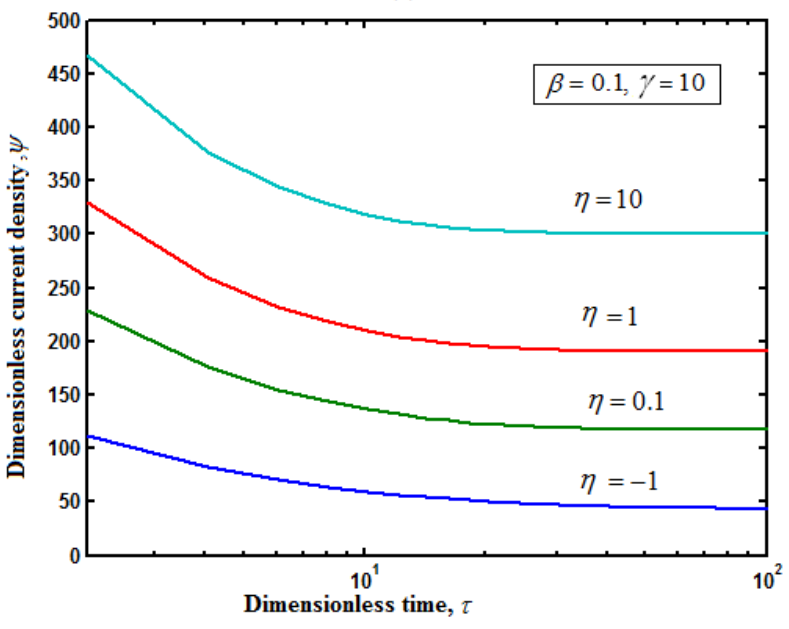


Fig. 6.Plot of dimensionless current density on (a-c) dimensionless potential for various values of parameters (d) dimensionless time for various values of potential using Eqn. (15).

(a)

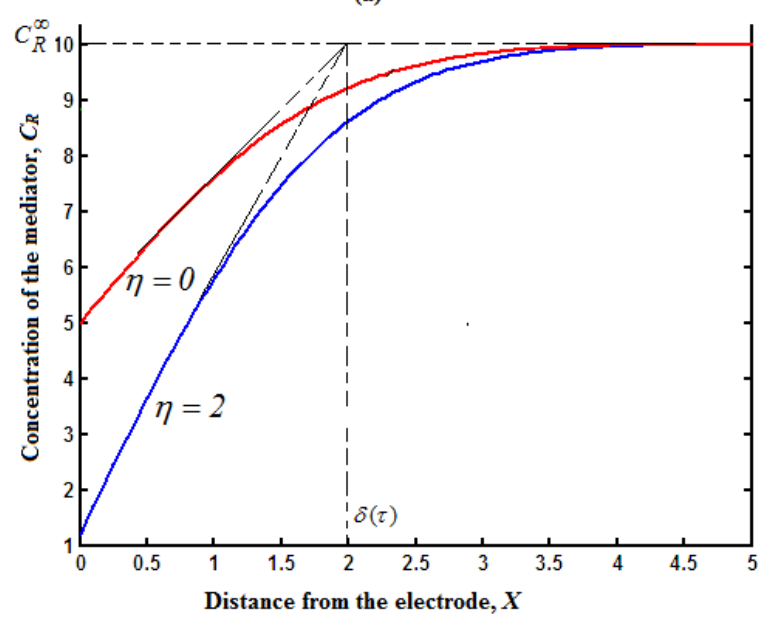

(a)

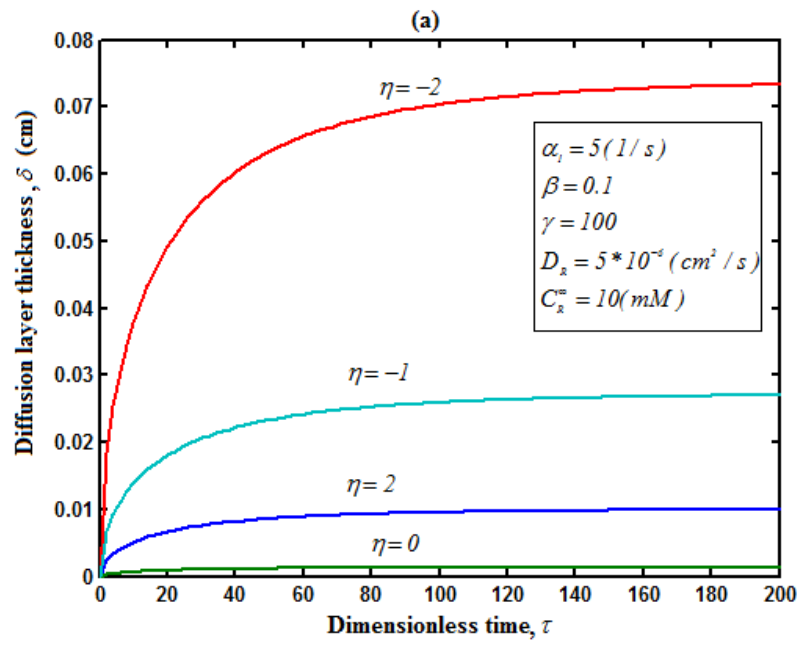

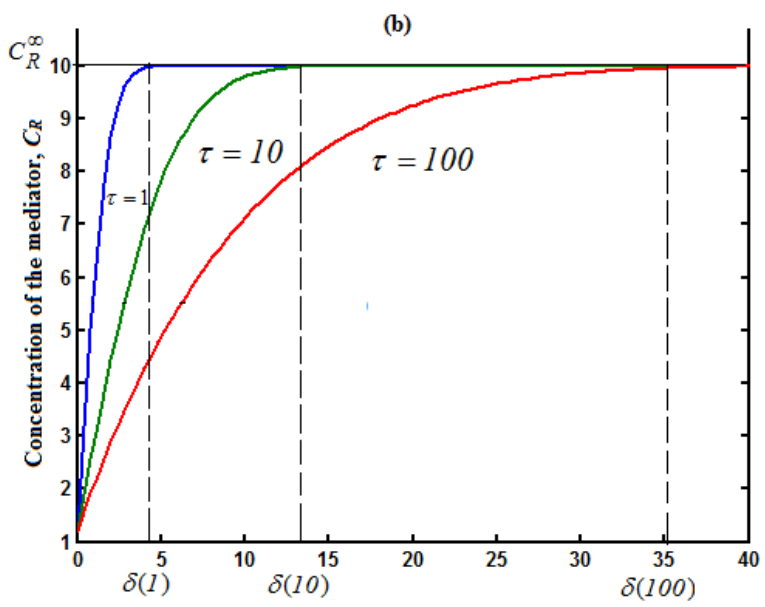

Distance from the electrode, $X$

(b)

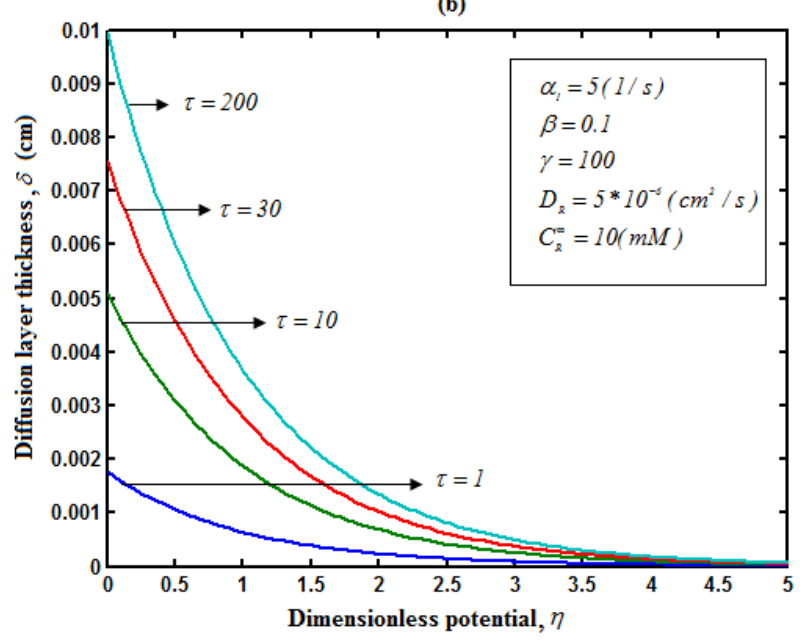

Fig.9.Plot of diffusion layer thickness versus current potential using Eqn. (31) 


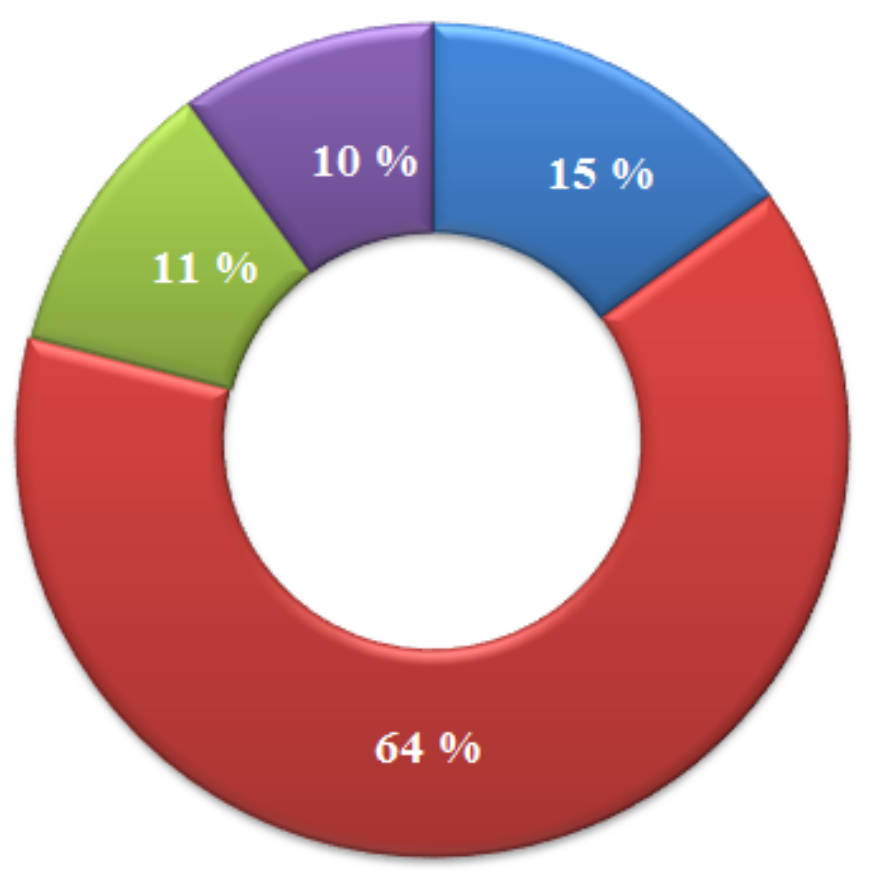

- Michaelis constant for the mediator, $\gamma$

- Potential, $\eta$

$\square$ Michaelis constant for the substrate, $\beta$

口 Dimensionless time, $\tau$

Fig.10.Sensitivity analysis of the parameters: Percentage change in dimensionless current density when $\beta=0.05, \gamma=5$ and $\eta=1$. 
Table 1 (a): Comparison of normalized non-steady-state concentration of oxidized mediator $u$ with simulation results for various values of $X$ and for some fixed values of $\beta=0.1, \gamma=100$ and $\eta=2$.

\begin{tabular}{|c|c|c|c|c|c|c|c|c|c|c|c|c|}
\hline \multirow[t]{3}{*}{$X$} & \multicolumn{12}{|c|}{ Substrate concentration $u$} \\
\hline & \multicolumn{3}{|c|}{$u$ (when $\tau=3$ ) } & \multicolumn{3}{|c|}{$u \quad($ when $\tau=15)$} & \multicolumn{3}{|c|}{$u$ (when $\tau=30$ ) } & \multicolumn{3}{|c|}{$u \quad$ (when $\tau=100$ ) } \\
\hline & $\begin{array}{l}\text { This } \\
\text { work } \\
\text { Eq.(13) }\end{array}$ & Simulation & $\begin{array}{l}\% \text { of error } \\
\text { deviation }\end{array}$ & $\begin{array}{l}\text { This } \\
\text { work } \\
\text { Eq.(13) }\end{array}$ & Simulation & $\begin{array}{l}\% \text { of } \\
\text { error } \\
\text { deviation }\end{array}$ & $\begin{array}{l}\text { This } \\
\text { work } \\
\text { Eq.(13) }\end{array}$ & Simulation & $\begin{array}{l}\% \text { of } \\
\text { error } \\
\text { deviatio } \\
\mathrm{n}\end{array}$ & $\begin{array}{l}\text { This } \\
\text { work } \\
\text { Eq.(13) }\end{array}$ & Simulation & $\begin{array}{l}\% \text { of } \\
\text { error } \\
\text { deviatio } \\
\mathrm{n}\end{array}$ \\
\hline 1 & 0.5968 & 0.5966 & 0.0335 & 0.7386 & 0.7384 & 0.0271 & 0.7687 & 0.7686 & 0.0130 & 0.7928 & 0.7928 & 0.0000 \\
\hline 2 & 0.3698 & 0.3699 & 0.0270 & 0.6073 & 0.6070 & 0.0494 & 0.6654 & 0.6652 & 0.0301 & 0.7129 & 0.7126 & 0.0421 \\
\hline 5 & 0.0355 & 0.0353 & 0.5634 & 0.2958 & 0.2954 & 0.1352 & 0.4079 & 0.4075 & 0.0981 & 0.5140 & 0.5148 & 0.1556 \\
\hline 7 & 0.0037 & 0.0037 & 0.0000 & 0.1621 & 0.1621 & 0.0000 & 0.2793 & 0.2794 & 0.0353 & 0.4100 & 0.4119 & 0.4631 \\
\hline 10 & 0.0000 & 0.0000 & 0.0000 & 0.0537 & 0.0537 & 0.0000 & 0.1449 & 0.1449 & 0.0000 & 0.2879 & 0.2851 & 0.9726 \\
\hline \multicolumn{4}{|c|}{ Average error \% } & \multicolumn{3}{|c|}{ Average error \% 0.0423} & \multicolumn{3}{|c|}{ Average error \% } & \multicolumn{3}{|c|}{ Average error \% } \\
\hline
\end{tabular}


Table 1(b): Comparison of normalized non-steady-state concentration of oxidized mediator $u$ with simulation results for various values of $\mathrm{X}$ and for some fixed values of $\beta=0.1, \gamma=100$ and $\tau=100$.

\begin{tabular}{|c|c|c|c|c|c|c|c|c|c|c|c|c|}
\hline \multirow[t]{3}{*}{$X$} & \multicolumn{12}{|c|}{ Substrate concentration $\mathrm{u}$} \\
\hline & \multicolumn{3}{|c|}{$u($ when $\eta=-2)$} & \multicolumn{3}{|c|}{$u($ when $\eta=0.1)$} & \multicolumn{3}{|c|}{$u \quad($ when $\eta=1)$} & \multicolumn{3}{|c|}{$u \quad$ (when $\eta=2$ ) } \\
\hline & $\begin{array}{l}\text { This } \\
\text { work } \\
\text { Eq.(13) }\end{array}$ & Simulatior & $\begin{array}{l}\% \text { of error } \\
\text { deviation }\end{array}$ & $\begin{array}{l}\text { This } \\
\text { work } \\
\text { Eq.(13) }\end{array}$ & Simulation & $\begin{array}{l}\% \text { of error } \\
\text { deviation }\end{array}$ & $\begin{array}{l}\text { This } \\
\text { work } \\
\text { Eq.(13) }\end{array}$ & Simulation & $\begin{array}{l}\text { \% of error } \\
\text { deviation }\end{array}$ & $\begin{array}{l}\text { This work } \\
\text { Eq.(13) }\end{array}$ & Simulation & $\begin{array}{l}\text { \% of error } \\
\text { deviation }\end{array}$ \\
\hline 1 & 0.1072 & 0.1072 & 0.0000 & 0.4725 & 0.4720 & 0.1058 & 0.6580 & 0.6580 & 0.0000 & 0.7928 & 0.7928 & 0.0000 \\
\hline 2 & 0.0964 & 0.0964 & 0.0000 & 0.4247 & 0.4246 & 0.0000 & 0.5916 & 0.5917 & 0.0169 & 0.7129 & 0.7126 & 0.0421 \\
\hline 5 & 0.0694 & 0.0692 & 0.2882 & 0.3061 & 0.3060 & 0.0000 & 0.4265 & 0.4262 & 0.0703 & 0.5140 & 0.5148 & 0.1557 \\
\hline 7 & 0.0554 & 0.0550 & 0.7220 & 0.2441 & 0.2454 & 0.5326 & 0.3402 & 0.3418 & 0.4703 & 0.4100 & 0.4119 & 0.4634 \\
\hline 10 & 0.0388 & 0.0385 & 0.7732 & 0.1714 & 0.1721 & 0.4084 & 0.2388 & 0.2397 & 0.3769 & 0.2879 & 0.2851 & 0.9726 \\
\hline \multicolumn{3}{|c|}{ Average error \% } & 0.3567 & \multicolumn{3}{|c|}{ Average error \% } & \multicolumn{3}{|c|}{ Average error \% } & \multicolumn{2}{|c|}{ Average error \% } & 0.3268 \\
\hline
\end{tabular}

